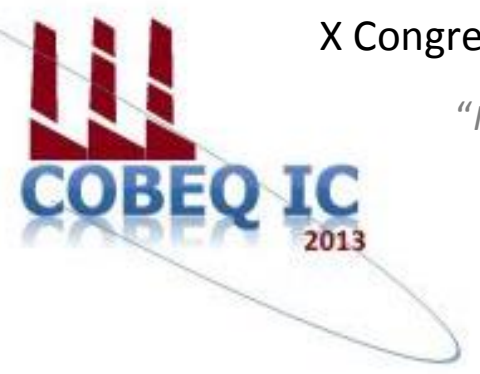

"Influência da pesquisa em Engenharia Química no desenvolvimento tecnológico e industrial brasileiro"

Universidade Federal Rural do Rio de Janeiro Universidade Severino Sombra Vassouras - RJ-Brasil

\title{
SÍNTESE DE CATALISADOR DO TIPO PEROVSKITA PARA PRODUÇÃO DE BIODIESEL
}

\author{
SANTIAGO**1 , T. S.A.; MARTINS ${ }^{2}$, M. I.; CARDOSO ${ }^{3}$, V.L. \\ ${ }^{1}$ Aluna da FEQ/UFU $\quad{ }^{2}$ Doutoranda da FEQ/UFU $\quad{ }^{3}$ Docente da FEQ/UFU \\ Faculdade de Engenharia Química - Universidade Federal de Uberlândia \\ Endereço - Av. João Naves de Ávila 2121- Uberlândia - MG - CEP 38408-100 \\ email: vicelma@ufu.br
}

\begin{abstract}
RESUMO - Transesterificação de óleos vegetais com metanol constitui-se uma das rotas alternativas para produção de Biodiesel, combustível biodegradável, derivado de fontes renováveis, permitindo a substituição do óleo diesel fóssil sem necessidade de alterações dos motores. A produção comercial de biodiesel é conduzida usualmente por reação catalítica homogênea empregando-se hidróxidos básicos como catalisadores. Esse processo apresenta alguns problemas tecnológicos como geração significativa de efluente e formação de sabão. Estas questões têm levado ao estudo e desenvolvimento de diferentes tipos de catalisadores para a produção de biodiesel, visando à simplificação do processo de separação do mesmo da mistura reacional e redução de etapas e volume de resíduos gerados. Portanto, apresenta-se nesse trabalho um estudo da transesterificação de óleo de soja em biodiesel usando perovskita $\left(\mathrm{CaZrO}_{3}\right)$ como catalisador. A perovskita foi obtida a partir de uma reação convencional e caracterizada por difração de raio X. A reação de transesterificação foi conduzida num reator encamisado a $64^{\circ} \mathrm{C}$, sob agitação magnética, acoplado a um condensador, variando-se o tempo de reação. Os resultados da cromatografia evidenciaram a transesterificação e a viabilidade de utilização de $\mathrm{CaZrO}_{3}$ como catalisador na produção de biodiesel. Estudos referentes à reutilização e atividade catalítica são necessários visando sua implementação comercial.
\end{abstract}

Palavras chave: combustível renovável, transesterificação catalítica, catálise heterogênea.

\section{INTRODUÇÃO}

O biodiesel, mistura de ésteres de ácidos graxos, é um combustível renovável, obtido principalmente a partir da transesterificação catalítica homogênea de óleos vegetais e gordura animal com álcoois, empregando-se hidróxidos básicos como catalisadores.
Usualmente, metanol é o álcool mais utilizado para a produção de biodiesel devido a seu baixo custo e disponibilidade (LEUNG et al., 2010).

Embora o processo homogêneo resulte em maiores rendimentos, principalmente para teor de ácidos graxos livres (FFA's) menores que $1 \%$, quando comparado à 
transesterificação catalítica heterogênea (KARMAKAR et al, 2010), o mesmo apresenta algumas desvantagens na sua aplicação, tais como: geração de grande quantidade de águas residuais durante a separação e purificação do produto e formação de subproduto indesejado (sabões) por reação do álcool com os FFA's presentes no meio reacional (SHARMA; SINGH, 2009); separação dispendiosa do catalisador homogêneo a partir da mistura reacional.

Dessa maneira, o desenvolvimento de catalisadores sólidos heterogêneos eficientes é relevante na busca de processos alternativos, que sejam economicamente viáveis, para a produção comercial de biodiesel. Óxidos metálicos representam o grupo de catalisadores básicos heterogêneos mais estudados na literatura; dentre eles tem-se o óxido de cálcio, óxido de magnésio, óxido de estrôncio, óxidos mistos e hidrotalcita (BORGES; DÍAZ, 2012).

Segundo Kouzu e Hidaka (2012), o óxido de cálcio $(\mathrm{CaO})$ apresenta um desempenho catalítico superior aos demais catalisadores sólidos básicos na transesterificação de óleos vegetais com metanol. Por outro lado, apresenta reação muito mais lenta que a transesterificação catalítica homogênea aplicada atualmente para a produção de biodiesel, além de ser facilmente envenenado com $\mathrm{CO}_{2}$ e $\mathrm{H}_{2} \mathrm{O}$ presentes no ar. Dessa forma, alguns pesquisadores têm testado a preparação de óxidos mistos a partir da combinação de $\mathrm{CaO}$ com outros óxidos metálicos, buscando aumentar sua atividade catalítica. Kawashima et al. (2008) estudaram diferentes óxidos mistos contendo $C a, B a, M g$ ou $L a$, sendo que os catalisadores contendo $\mathrm{Ca}$ apresentaram alta atividade e rendimentos de aproximadamente $90 \%$ de metil éster .

Assim, neste trabalho investigou-se a transesterificação de óleo de soja para produção de biodiesel usando metanol e catalisadores básicos sólidos do tipo perovskita $\left(\mathrm{CaZrO}_{3}\right), \quad$ sintetizado em laboratório.

\section{MATERIAIS E MÉTODOS}

\section{Preparação do catalisador}

$\mathrm{O}$ catalisador $\mathrm{CaZrO}_{3}$, foi sintetizado utilizando-se o método do estado sólido, a partir de uma mistura equimolar de $\mathrm{ZrO}_{2}$ e $\mathrm{CaCO}_{3}$, conforme descrito por Kawashima et al. (2008). A mistura foi moída e posteriormente calcinada. A calcinação foi realizada com fluxo de ar $(\mathrm{Qar}=30 \mathrm{~mL} / \mathrm{min})$ até $500^{\circ} \mathrm{C}$ a uma taxa de $2^{\circ} \mathrm{C} / \mathrm{min}$, mantida por $2 \mathrm{~h}$ nessa temperatura e elevadas até $1050^{\circ} \mathrm{C}$ à mesma taxa, mantida nessa temperatura por 4h. As amostras de catalisador obtidas foram acondicionadas em um dessecador.

\section{Caracterização da estrutura do catalisador}

A caracterização da estrutura do catalisador foi obtida pelo método de difração de raio $\mathrm{X}(\mathrm{DRX})$. Os ensaios foram realizados num difratômetro Shimadzu, modelo XRD600, com fonte de radiação monocromática de $\mathrm{CuK} \alpha$ obtida por $40 \mathrm{kV}$ em corrente de filamento de $30 \mathrm{~mA}$. As medidas foram feitas com um intervalo de varredura de $2 \theta$ entre 10 e $80^{\circ}$ e passo de $0,02^{\circ}$ a uma velocidade de $1,2 \%$ min.

\section{Reação de Transesterificação}

O catalisador sintetizado nesse trabalho foi testado na reação de transesterificação do óleo de soja comercial com metanol. As reações foram conduzidas à pressão atmosférica, em reator batelada encamisado com capacidade de $50 \mathrm{~mL}$, sob agitação magnética, acoplado a um condensador. O produto final foi evaporado a vácuo para remover o excesso de metanol e o catalisador foi separado por centrifugação a 8000rpm durante $10 \mathrm{~min}$ e posteriormente separado do glicerol utilizando-se um funil de separação.

Os experimentos foram conduzidos à temperatura de $64^{\circ} \mathrm{C}$, com $8 \%$ (base mássica) de catalisador, a uma razão molar (RM) metanol/óleo 7:1, variando-se o tempo de reação conforme apresentado na Tabela 1 . As condições reacionais foram escolhidas com base no trabalho de Kawashima (2008). 
Tabela 1 - Condições reacionais dos experimentos usando perovskita como catalisador sólido para a reação de produção de biodiesel

\begin{tabular}{ccc}
\hline Experimento & $\begin{array}{c}\text { RM } \\
\text { (metanol/óleo) }\end{array}$ & $\begin{array}{c}\text { Tempo de } \\
\text { reação(h) }\end{array}$ \\
\hline 1 & $7: 1$ & 3 \\
2 & $7: 1$ & 5 \\
3 & $7: 1$ & 7 \\
4 & $7: 1$ & 10 \\
\hline
\end{tabular}

A qualidade do biodiesel bruto produzido foi avaliada pela medição do teor de ésteres metílicos de ácidos graxos (\% FAME). A medida da porcentagem de FAME foi realizada num cromatógrafo gasoso CG2010AF equipado com injetor Split/splitelss da Shimadzu e autoinjector AOC-20i acoplado a um detector de ionização de chama (FID) e uma coluna capilar específica para a separação de ácidos graxos, RTX-WAX, de $30 \mathrm{~m} \times 0,25$ x $0.25 \mu \mathrm{m}$, usando hélio como gás de arraste . Uma solução de heptadecanoato de metila foi usada como padrão interno.

\section{RESULTADOS E DISCUSSÃO}

\section{Caracterização do catalisador}

$\mathrm{O}$ difratograma do óxido misto tipo perovskita sintetizado e utilizado neste trabalho é apresentado na Figura 1, sendo típico do óxido misto tipo perovskita com razão $\mathrm{Mg} / \mathrm{Al}=1$ calcinado a $1050^{\circ} \mathrm{C}$ por $4 \mathrm{~h}$. Difratograma similar, para o mesmo óxido misto é apresentado por Kawashima et al. (2008).

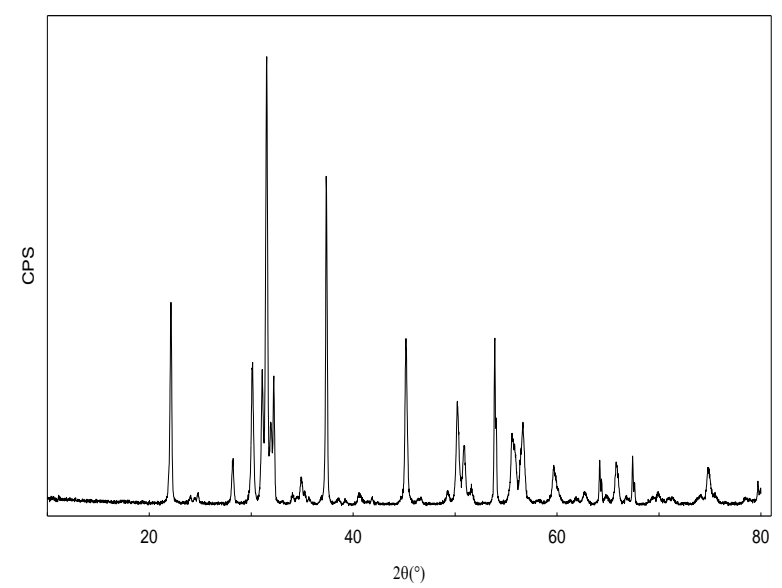

Figura 1 - Difratograma de raios-X da amostra de $\mathrm{CaZrO}_{3}$ com estrutura do tipo perovskita.

\section{Reação de transesterificação}

Os resultados obtidos na reação de transesterificação do óleo de soja com metanol, usando $\mathrm{CaZrO}_{3}$ como catalisador é apresentado na figura 2 a seguir. A \% de FAME obtida em 10 horas de reação foi de $97,4 \%$, significando que o catalisador sintetizado apresenta boa atividade nas condições propostas neste trabalho.

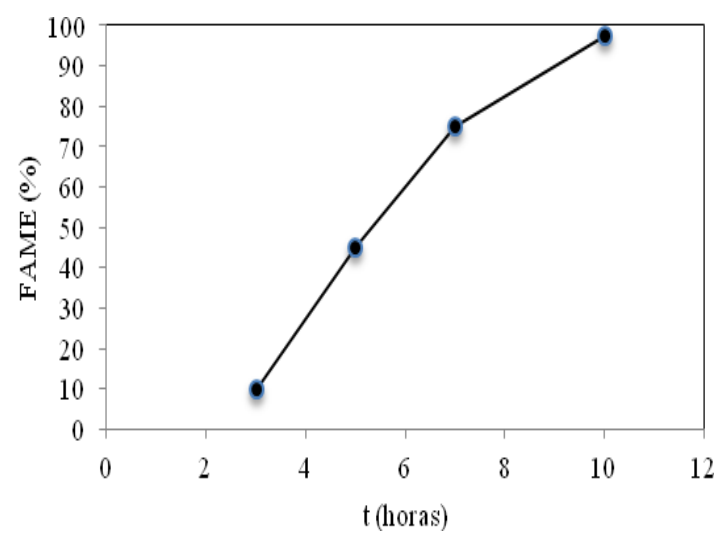

Figura 2 - Perfil de éster metílico na reação de transesterificação com metanol para o catalisador $\mathrm{CaZrO}_{3}$.

\section{CONCLUSÃO}

A transesterificação usando-se hidrotalcita perovkita como catalisadores básicos heterogêneos mostra-se promissora para a produção de biodiesel. A otimização do sistema reacional, ou seja, quantidade de catalisador, tempo de reação e razão molar (RM) metanol/óleo, bem como, a capacidade de reutilização desses catalisadores devem ser alvo de estudos para viabilizá-los comercialmente. $\mathrm{O}$ rendimento (\%FAME), fator preponderante na escolha do catalisador a ser usado na transesterificação de óleos vegetais para produção de biodiesel, também deve ser alvo de estudo minucioso a fim de que se possa escolher o catalisador que demonstre a maior eficiência catalítica.

\section{REFERÊNCIAS}

\section{BORGES, M. E.; DÍAZ, L. Recent} developments on heterogeneous catalysts for biodiesel production by oil esterification and transesterification reactions: A review. Renewable and 
Sustainable Energy Reviews, v.16, p. 2839-2849, 2012.

KARMAKAR, A., KARMAKAR, S.;

MUKHERJE, S. Properties of various

plants and animals feedstocks for biodiesel production. Bioresource

Technology, 2010.

KAWASHIMA, A.; MATSUBARA, K.;

HONDA, K. Development of

heterogeneous base catalysts for biodiesel

production. Bioresource Technology, v.

99, p. 3439-3443, 2008.

KOUZU, M.; HIDAKA, J. Transesterification of vegetable oil into biodiesel catalysed by $\mathrm{CaO}:$ A review. Fuel, v. 93, p. 1-12, 2012.

LEUNG, D. Y.C.; WU, X. ; LEUNG, M.K.H; A review on biodiesel production using catalyzed transesterification. Applied Energy, v. 87, p. 1083 - 1095, 2010.

SHARMA Y.C.; SINGH, B. Development of biodiesel: current scenario.

Renewableand Sustainable Energy

Reviews, V.13, P.1646-51, 2010

\section{AGRADECIMENTOS}

Os autores agradecem a FAPEMIG, CNPQ, CAPES e VALE pelo apoio financeiro. 